\title{
A LATE PLEISTOCENE ENDEMIC GENET (CARNIVORA, VIVERRIDAE) FROM AGHIA NAPA, CYPRUS
}

\author{
Theodorou G. E. ${ }^{1}$, Roussiakis S. I. ${ }^{1}$, Athanassiou A. ${ }^{1,2}$, \\ Giaourtsakis I. ${ }^{3}$, and Panayides $\mathrm{I}^{4}$
}
${ }^{1}$ National and Kapodistrian University of Athens, Faculty of Geology and Geoenvironment, Department of Historical Geology and Palaeontology, 15784 Athens, Greece, gtheodor@geol.uoa.gr,srousiak@geol.uoa.gr,aathanas@geol.uoa.gr
${ }^{2}$ Hellenic Ministry of Culture, Department of Palaeoanthropology-Speleology, Ardittou 34B, 11636 Athens, Greece
${ }^{3}$ Ludwig-Maximilians-Universität München, Department of Geo-and Enviromental Sciences, Section of Paleontology, Richard-Wagner-Str. 10, D-80333 Munich, Germany, i.giaourtsakis@lrz.uni-muenchen.de
${ }^{4}$ Cyprus Geological Survey, 1415 Nicosia, Cyprus, ipanayides@gsd.moa.gov.cy

\begin{abstract}
The Pleistocene endemic fauna of Cyprus consists mainly of dwarf hippos and elephants, adapted to the insular environment. Among the rare elements of this endemic fauna is a small carnivore, the viverrid Genetta plesictoides, poorly known from scanty material that comes from two localities. Recent excavations in a rockshelter site at the area of Aghia Napa yielded-apart from a rich hippo samplenew skeletal remains (a partial skull and a tibia) of the cypriot genet. The dental morphology shows adaptations towards a more carnivorous diet in relation to the extant Genetta genetta.
\end{abstract}

Key words: Mediterranean, Cyprus, Genetta plesictoides, Insular Endemism.

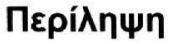

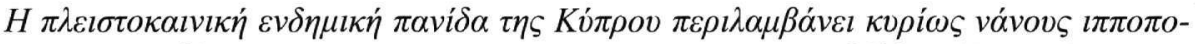

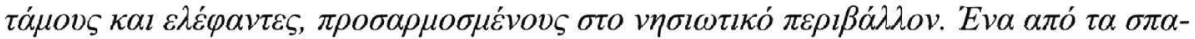

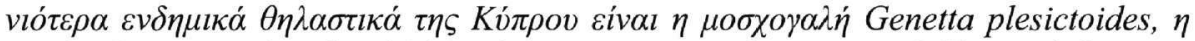

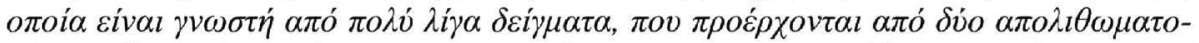

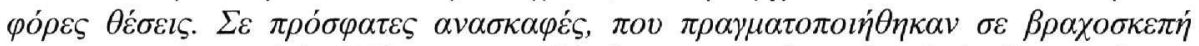

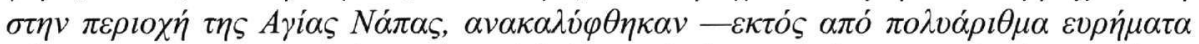

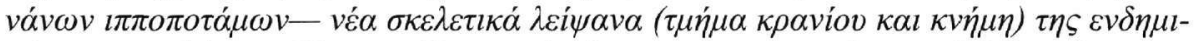

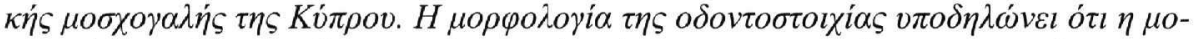

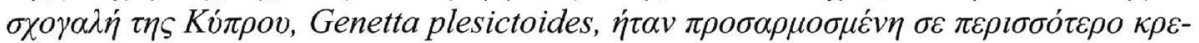

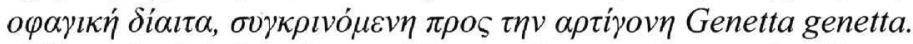

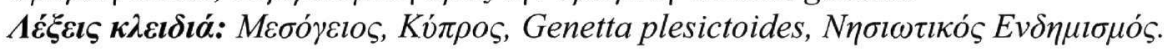




\section{Introduction}

Many Mediterranean islands are renowned for their endemic Pleistocene mammalian faunas. These faunas are usually greatly impoverished and ecologically unbalanced, and include large animals that are able to cross wide sea barriers to reach remote islands. This type of sporadic and highly selective dispersal from a continent to an island has been called a 'Sweepstake Migration' (Simpson 1940, Sondaar 1977, Dermitzakis and Sondaar 1979). The population that reaches an island this way becomes genetically isolated from the parent continental population and undergoes a rapid evolutionary adaptation in the new insular environment, usually affecting the body size and the pattern of locomotion (Sondaar 1977, Lomolino 2005, Palombo in press). The sweepstake migrations and the subsequent evolution of endemic faunas were facilitated during the Pleistocene, as the climatically induced sea-level fluctuations were changing the distance between the mainland and the islands. The low sea levels were making the sea barrier easier and more probable to cross, while the subsequent high levels could make the sea channel crossing practically impossible, causing the isolation of the founding population on an island. The great number of islands in the Mediterranean, especially in the Aegean, made this region highly favourable for the evolution of island endemics (Sondaar and Boekschoten 1967, Dermitzakis and Sondaar 1979, Kotsakis et al. 1980, Sondaar et al. 1986, Marra 2005, Palombo 2006).

Animals that can migrate using sweepstake routes include mainly those with good swimming capabilities over long distances, i.e. elephants, deer and hippopotamuses, as well as flying animals as birds and bats (Sondaar 1977). Small animals, like rodents and lizards, can also reach a remote island by rafting. Carnivore taxa are normally not expected in insular endemic faunas of 'sweepstake' origin, as they are not long distance swimmers. Therefore, carnivores found on today's islands are probably not colonizers, but insular relics from a time when a mainland-island connection existed (Meiri et al. 2004). The usual carnivores of the Mediterranean insular faunas are the otters, which are adapted to aquatic lifestyle (Willemsen 1992). Other occurrences include the canid Cynotherium sardous of Sardinia-Corsica (Malatesta 1962, Eisenmann and van der Geer 1999, Lyras et al. 2006) and the genet Genetta plesictoides from Cyprus (Bate 1903a).

Cyprus, as an oceanic island that was separated from the mainland for a very long time, has yielded a greatly impoverished endemic fauna (Bate 1904, Boekschoten and Sondaar 1972, Reese 1995). The main element is a dwarf hippopotamus, Phanourios minor (Desmarest 1822), known from more than 30 sites on the island (Forsyth Major 1902, Bate 1906, Boekschoten and Sondaar 1972, Reese 1995, Reese in Simmons 1999: p.162). Another common endemic species is Elephas cypriotes Bate 1903, a dwarf elephant (Bate 1903b, 1905). Some scanty elephant remains of somewhat larger size than E. cypriotes may represent another endemic elephant species (Boekschoten and Sondaar 1972). Other, generally quite sparse, findings include the afore mentioned genet Genetta plesictoides, as well as some not well known small mammals: one or two species of murid rodents (Mus sp.), one or two species of bats and a soricid insectivore (Crocidura suaveolens) (Boekschoten and Sondaar 1972, Reese 1995). Endemic fossil deer, a common element in other Mediterranean insular faunas, have not been found on the island.

Recently (2001-2003), the Geological Survey of Cyprus and the Department of Historical Geology and Palaeontology of the University of Athens carried out an excavation in a rockshelter site in the eastern part of the island, near the town of Aghia Napa. The site is situated about $1 \mathrm{~km}$ east of the town of Aghia Napa (Fig. 1). It yielded abundant material of the dwarf hippo Ph. minor, as well as cranial and postcranial finds of the small carnivore of Cyprus. The new material of this endemic genet is described in the present paper.

\section{Geological setting}

The basement of the Aghia Napa area is a Late Cretaceous mélange that comprises bentonitic clays, containing blocks of siliciclastic sandstones, lava, pelagic limestones and red radiolarites. 
The mélange is overlain by the Late Cretaceous - Early Miocene Lefkara Formation consisting of pelagic chalks with chert intercalations. Patch reefs of the Terra Member (Pakhna Formation) are extensively exposed on the surface overlying Lefkara Formation. The Aquitanian-Burdigalian Terra limestone remnants only rarely reflect reef morphology following Miocene and Pleistocene erosion. The reef facies comprises small frame stone structures made up of massive and branching corals as well as of encrusting organisms such as red algae, foraminiferans, bryozoans and molluscs. Among the coral colonies there is coarse bioclastic debris comprising fragments of bivalves, gastropods, echinoderms, algae, foraminiferans as well as aggregate grains and lime mud. Coral-dominated patch reefs passed outwards into algae-dominated deposits, foraminiferal packstones, grainstones and pelagic carbonates.

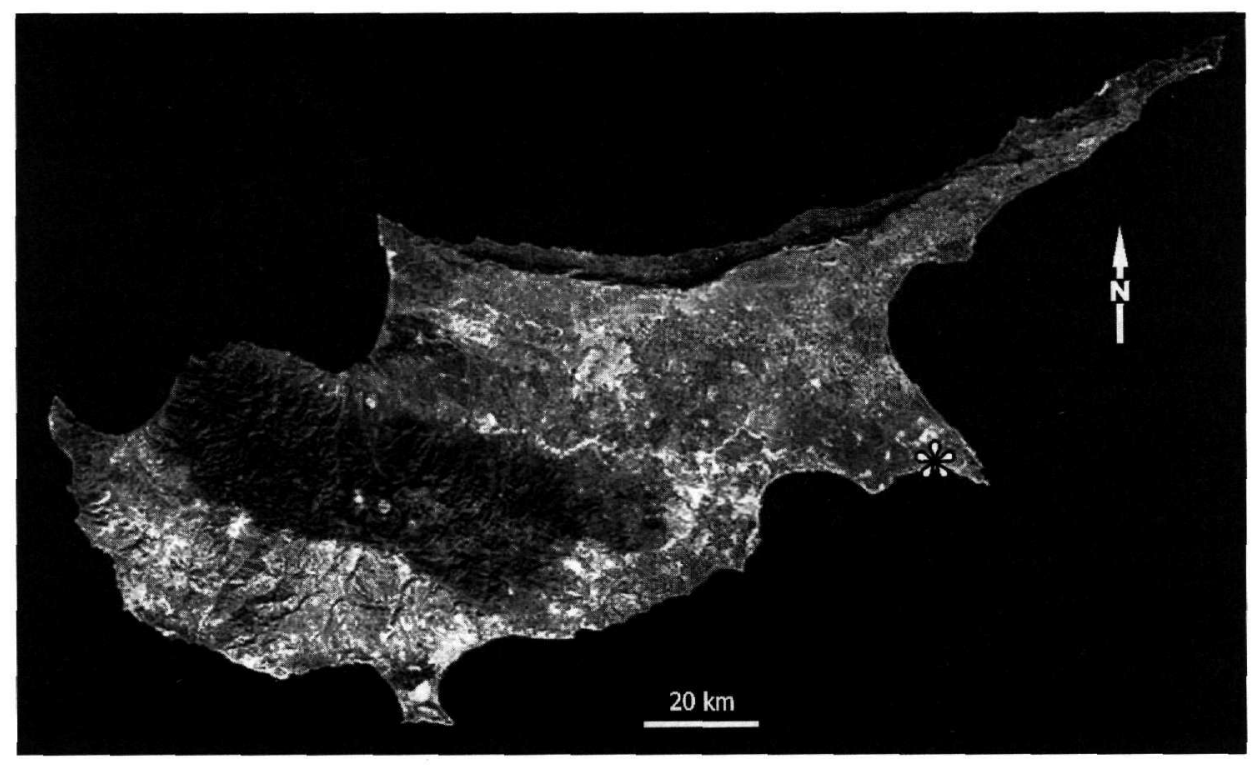

Figure 1 - Satellite image of Cyprus (source: NASA, http://visibleearth.nasa.gov/). The position of the Aghia Napa site is indicated with an asterisk

The rockshelter site of Aghia Napa is filled with clays of terrestrial origin, arranged in horizontal layers. The superficial layers are partly disturbed and the fossil hippopotamus bones are moved and mixed with recent bones. The genet remains were found during the October 2002 excavation, in the square Q8, together with numerous Phanourios remains. The sediment at Q8 was completely undisturbed. Due to local erosion, the finds were quite close to the surface (depth: 35 $\mathrm{cm}$ ). ESR datings carried out on Phanourios teeth in the National Centre of Scientific Research 'Demokritos' in Athens, yielded ages of 11.0-13.5 ka for the Aghia Napa site (Bassiakos pers. com.).

\section{Taxonomy}

Order: Carnivora Bowdich, 1821

Family: Viverridae Gray, 1821

Genus: Genetta Oken, 1816

Genetta plesictoides Bate, 1903

Material: Partial skull with the right C-M1 and the left P2-M1 (AN-90.1, Fig. 2); right tibia (AN90.2). All specimens were found close together in the same pocket and presumably belong to the same individual. 


\subsection{Description}

The skull is narrow and elongated (estimated condylobasal length: $86 \mathrm{~mm}$ ), with moderately long and low rostrum, which occupies about $1 / 3$ of the skull length. The infraorbital foramen is large and almost circular $(3.9 \times 3.4 \mathrm{~mm})$, and opens above the parastyle of P4. The orbital fossa is large and its anterior margin is slightly behind the infraorbital foramen's level.

Due to the deformation of the specimen, the cranial measurements are not accurate. The width of the skull at the supraorbital processes measures approximately $20 \mathrm{~mm}$, while at the constriction behind the postorbital processes it measures approximately $12 \mathrm{~mm}$. The maximal width of the braincase is estimated to $26 \mathrm{~mm}$.

The sagittal crest is very thin, Y-shaped anteriorly, and slightly more developed at the posterior part of the cranial roof. The choanae open $4 \mathrm{~mm}$ behind the M1.

The tympanic bulla is elongated, twice as long as it is wide $(16.5 \times 8.8 \mathrm{~mm})$. It is characterised by the marked antero-posterior elongation of the entotympanic chamber and the absence of an external auditory meatus tube.

The upper dentition is well preserved on the right side except for the incisors.

The P1 is very small and single-rooted. It is separated by diastemata of $1.5 \mathrm{~mm}$ from the canine and the P2. The P2 is elongated and narrow. Its main cusp is located slightly anteriorly in relation to the middle-length of the tooth. The distal crest of the main cusp is more trenchant than the mesial one and exhibits a tiny accessory cusp. The posterior part of the crown is elevated forming a cusp at the distalmost part of the tooth. There is a slightly developed lingual cingulum that extends to the mesial end of the tooth.

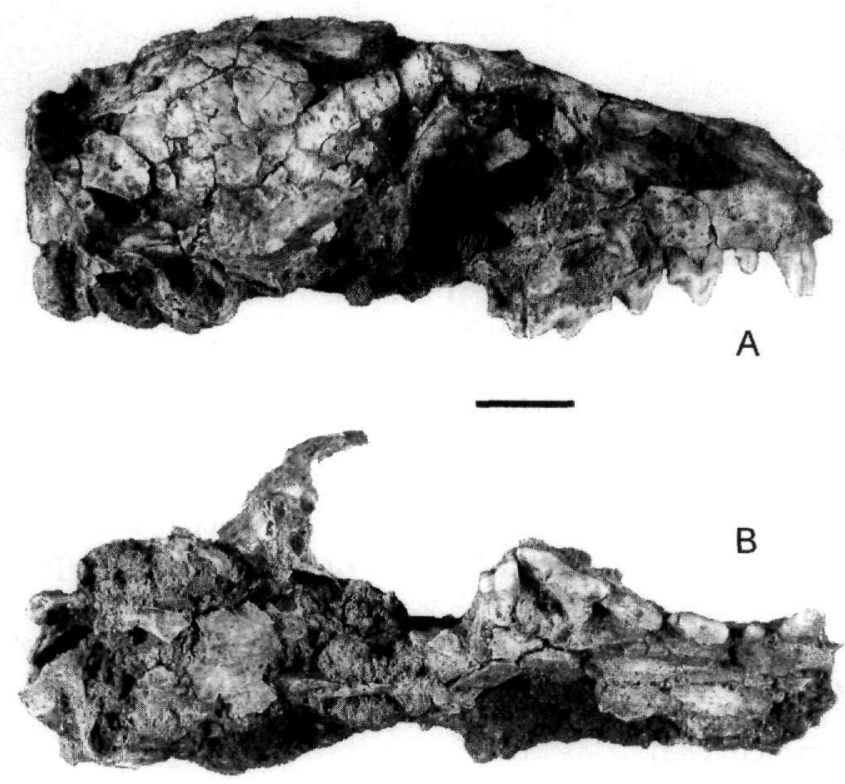

Figure 2 - Genetta plesictoides from Aghia Napa, Cyprus; skull: $A$, right lateral view; $B$, ventral view. Scale: $10 \mathrm{~mm}$

The P3 is similar to P2 but its main cusp is more symmetrically placed, while there is also a small accessory cusp at the base of the crown and anteriorly. There is no lingual cusp. 
The P4 is long and narrow, and has a very small and low parastyle, while the metastyle is clearly smaller in length than the paracone. The tip of the paracone is directed backwards. The protocone is weak, does not protrude significantly lingually, and does not extend mesially beyond the parastyle level. There is a cingulum at the lingual side of the metastyle.

The M1 is subtriangular and transversely elongated. Its mesial margin is convex, while the distal one is slightly concave. The ridge of the paracone is strong, elongated and transversely directed, whereas that of the metacone is very weak and low.

The M2 is lacking and no alveolus is observed behind M1. However, the region posteriorly of M1 is not well preserved and it is possible that a very small M2 did exist.

The tibia has the typical morphology of the family. Its total length is $74.2 \mathrm{~mm}$. The proximal articulation dimensions are DAPprox. $=13.3 \mathrm{~mm}$, DTprox. $=14.5 \mathrm{~mm}$. The distal articulation dimensions are DAPdist. $=6.2 \mathrm{~mm}$, DTdist. $=10.8 \mathrm{~mm}$.

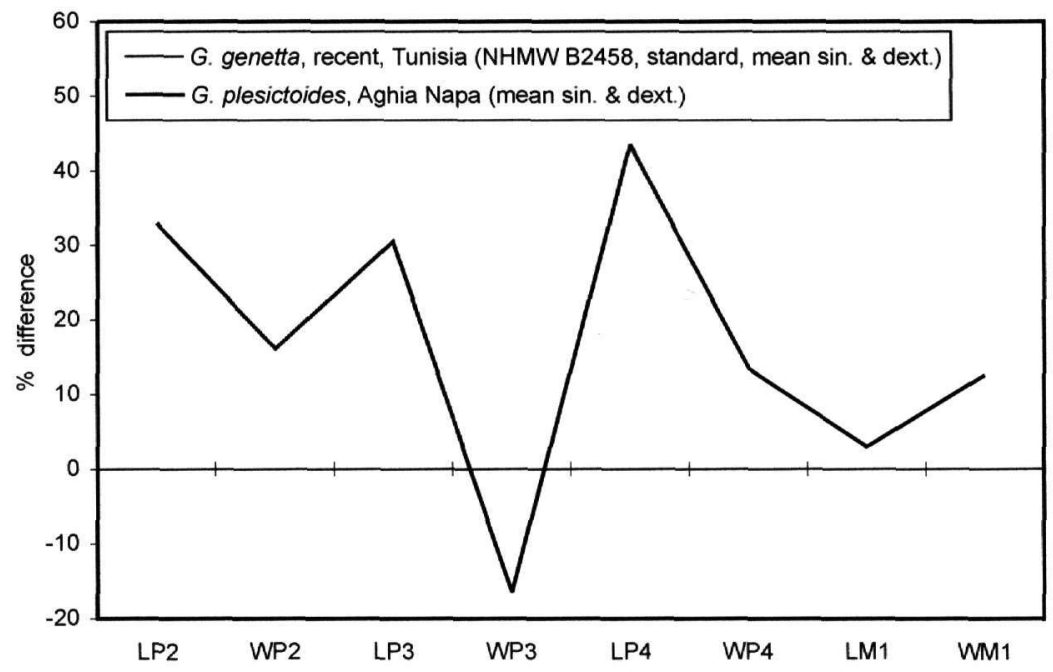

Figure 3 - Diagram comparing the dental dimensions of $G$. plesictoides from Aghia Napa, Cyprus and extant $G$. genetta from Tunisia

\section{Discussion}

The holotype of the endemic species Genetta plesictoides is a mandible found in the cave 'Dikomo Mandra' at Kerynia range in the northern part of Cyprus (Bate 1903a). Later, Steensma and Reese (in Simmons 1999: p.167-169) described a few juvenile carnivore remains from Aetokremnos that they referred to $G$. cf. plesictoides. Both samples are not comparable to the material described herein, as they represent different skeletal parts. However, their size - superior in comparison to that of G. genetta - is very similar, allowing us to ascribe the studied material to G. plesictoides.

In general, the upper dentition of the studied $G$. plesictoides cranial specimen appears to be very similar in morphology to the dentition of the extant $G$. genetta. Nevertheless, it exhibits important differences in some respects. The premolars (P2-P4) of G. plesictoides have different proportions, being longer and transversely narrowed. The P3 lacks the internal cusp that characterises the extant $G$. genetta, as well as the extant $G$. servalina, G. felina and G. tigrina. Contrary to these species, the protocone of $\mathrm{P} 4$ does not project lingually so much and is much less developed. Moreover, compared to G. genetta, the P4 is longer in relation to the other premolars (especially P3) or the whole cheek teeth series. It is not clear if the M2 is absent in G. plesictoides. However, if present, 
this tooth must have been diminutive, much smaller than in G. genetta, and about as small as in Osbornictis (van Rompaey 1988: fig. 3).

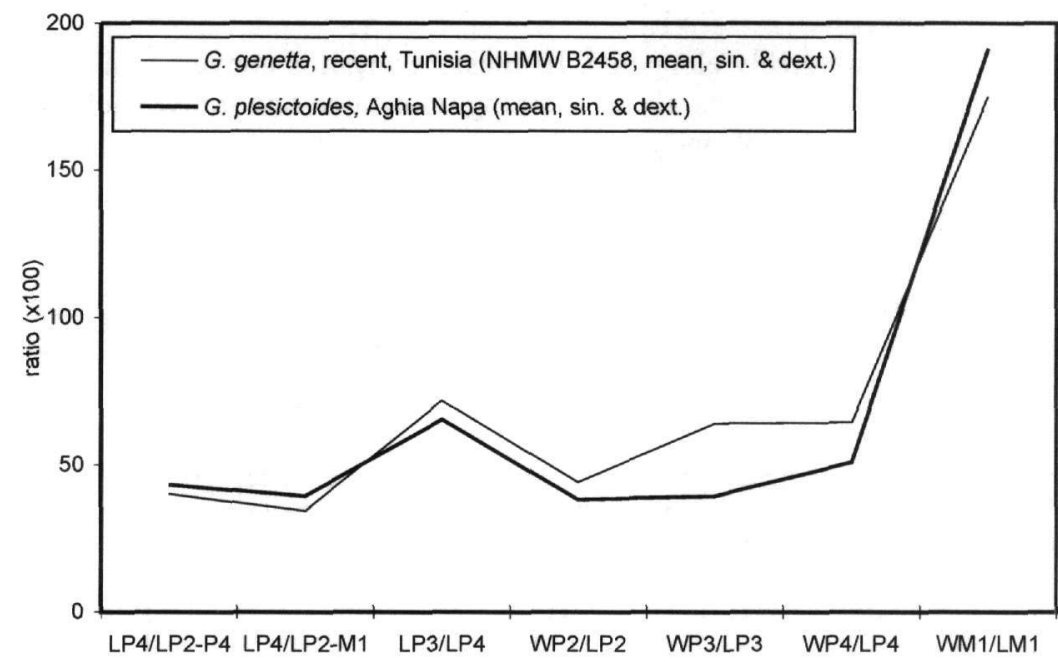

Figure 4 - Diagram comparing the dental proportions of $G$. plesictoides from Aghia Napa, Cyprus and extant G. genetta from Tunisia

Table 1 - Teeth measurements (in mm) of G. plesictoides from Cyprus, compared to extant $G$. genetta

\begin{tabular}{|c|c|c|c|}
\hline & \multicolumn{2}{|c|}{$\begin{array}{c}\text { Genetta plesictoides } \\
\text { Aghia Napa, Cyprus } \\
\text { sin. }\end{array}$} & $\begin{array}{c}\text { Genetta genetta } \\
\text { NHMW B2458, Tunisia } \\
\text { (recent, mean sin. \& dext.) }\end{array}$ \\
\hline$(\mathrm{L} \times \mathrm{W}) \mathrm{C}$ & - & $4.1 \times 2.9$ & - \\
\hline$(\mathrm{L} \times \mathrm{W}) \mathrm{P} 1$ & - & $2.5 \times 1.6$ & - \\
\hline$(\mathrm{L} \times \mathrm{W}) \mathrm{P} 2$ & $6.3 \times 2.4$ & $6.2 \times 2.4$ & $4.7 \times 2.1$ \\
\hline$(\mathrm{L} \times \mathrm{W}) \mathrm{P} 3$ & $6.6 \times(2.5)$ & $6.5 \times 2.7$ & $5.0 \times 3.1$ \\
\hline$(\mathrm{L} \times \mathrm{W}) \mathrm{P} 4$ & $10.0 \times 5.1$ & $10.1 \times 5.1$ & $7.0 \times 4.5$ \\
\hline$(\mathrm{L} \times \mathrm{W}) \mathrm{M} 1$ & $4.1 \times 7.9$ & $4.0 \times 7.6$ & $3.9 \times 6.9$ \\
\hline LP2-P4 & 23.1 & 23.2 & 17.4 \\
\hline LP2-M1 & 25.4 & 25.5 & 20.3 \\
\hline$(\mathrm{LP} 4 / \mathrm{LP} 2-\mathrm{P} 4) \times 100$ & 43.2 & 43.3 & 40.0 \\
\hline$(\mathrm{LP} 4 / \mathrm{LP} 2-\mathrm{M} 1) \times 100$ & 39.3 & 39.5 & 34.3 \\
\hline$(\mathrm{LP} 3 / \mathrm{LP} 4) \times 100$ & 66.1 & 64.6 & 71.9 \\
\hline$(\mathrm{WP} 2 / \mathrm{LP} 2) \times 100$ & 37.7 & 38.7 & 44.2 \\
\hline$(\mathrm{WP} 3 / \mathrm{LP} 3) \times 100$ & $(37.9)$ & 40.9 & 64.1 \\
\hline$(\mathrm{WP} 4 / \mathrm{LP} 4) \times 100$ & 51.4 & 50.5 & 64.4 \\
\hline$(\mathrm{WM} 1 / \mathrm{LM} 1) \times 100$ & 192.7 & 190.0 & 175.0 \\
\hline
\end{tabular}




\section{Conclusion}

The species $G$. plesictoides is a poorly known endemic viverrid. Apart from an adult mandible and scarce limb bones, as well as some scanty juvenile dental and postcranial material, no other skeletal parts of this small carnivore were known until recently. The new material from Aghia Napa is the first adult skull and upper dentition of the species. Its main character is the development of the cutting function of the dentition, probably reflecting a more carnivorous diet, compared to the extant common genet.

The co-occurrence of G. plesictoides with Phanourios minor in the site of Aghia Napa, positively indicates that the Cypriot genet belongs to the endemic Pleistocene fauna or is at least closely associated with it.

\section{Acknowledgments}

The excavations were financed by the General Secretariat of Research and Technology of the Greek Ministry of Development (EU project, Code 2013555 - Project of University of Athens 70/3/6050), the Ministry of Agriculture, Natural Resources and Environment of Cyprus, the Cyprus Geological Survey, the Municipality of Aghia Napa - Project UoA 70/3/6017) and the Special Account for Research Grants of Athens University (Project of UoA 70/4/3370). Special studies were financed by the Project on the Palaeontology of Cyprus (70/3/7093).

Special thanks are also owed to Dr Mathias Harzhauser, director of the Geological Department of the Natural History Museum of Vienna (NHMW), Dr Heinz Kollmann (NHMW), Helga Schmitz, librarian at the Geological and Palaeontological Department of the NHMW, Dr Barbara Herzig, Director of the Zoological Department of NHMW, Alex Lukendeker, Alexander Bibl, and Alice Schumacher (NHMW). This study would have been impossible without the help of Adrian Lister (University College London) and Andy Currant, curator of fossil vertebrates at the Natural History Museum London. Acknowledgments are owed to Varvara Perikleous, (Mayor of Aghia Napa), Athos Georgiou (Aghia Napa), George Petridis and Polis Michailidis (former and present Directors of the Cyprus Geological Survey), and Efthymios Tsiolakis (Cyprus Geological Survey) for their support since 2001. Special thanks are also due to Dr I. Bassiakos (NCSR 'Demokritos', Athens), who provided us with the absolute dating of the hippo material.

Last but not least, the authors thank two anonymous reviewers, whose comments and suggestions contributed to the amendment of the manuscript.

\section{References}

Bate, D.M., 1903a. On an extinct species of genet (Genetta plesictoides, sp. n.) from the Pleistocene of Cyprus, Proceedings of the Zoological Society of London, 1903(2), 121-124.

Bate, D.M., 1903b. Preliminary note on the discovery of a pygmy elephant in the Pleistocene of Cyprus, Proceedings of the Royal Society of London, 71, 498-500.

Bate, D.M., 1904. On the ossiferous cave-deposits of Cyprus, Geological Magazine, 1(5), 324325.

Bate, D.M., 1905. Further note on the remains of Elephas cypriotes from a cave-deposit in Cyprus, Philosophical Transactions of the Royal Society of London, 197, 347-360.

Bate, D.M., 1906. The pigmy Hippopotamus of Cyprus, Geological Magazine, 3, 241-245.

Boekschoten, G.J., and Sondaar, P.Y., 1972. On the fossil Mammalia of Cyprus, Proceedings of the Koninklijke Nederlandse Akademie van Wetenschappen, 75(4), 306-338. 
Dermitzakis, M.D., and Sondaar, P.Y., 1979. The importance of fossil mammals in reconstructing paleogeography with special reference to the Pleistocene Aegean Archipelago, Annales Géologiques des Pays Helléniques, 29, 808-840.

Eisenmann, V., and van der Geer, B., 1999. The Cynotherium from Corbeddu (Sardinia): comparative biometry with extant and fossil canids, Deinsea, 7, 147-168.

Forsyth Major, C.J., 1902. On the pigmy Hippopotamus from the Pleistocene of Cyprus, Proceedings of the Zoological Society of London, 1902(2), 107-112.

Kotsakis, T., Petronio, C., and Sirna, G., 1980. The Quaternary Vertebrates of the Aegean islands: palaeogeographical implications, Annales Géologiques des Pays Helléniques, 30(1), 31-64.

Larivière, S., and Calzada, J., 2001. Genetta genetta, Mammalian Species, 680, 1-6.

Lomolino, M.V., 2005. Body size evolution in insular vertebrates: generality of the island rule, Journal of Biogeography, 32(10), 1683-1699.

Lyras, G.A., van der Geer, A.A.E., Dermitzakis, M.D., and de Vos, J., 2006. Cynotherium sardous, an insular canid (Mammalia: Carnivora) from the Pleistocene of Sardinia (Italy), and its origin, Journal of Vertebrate Paleontology, 26(3), 735-745.

Malatesta, A., 1962. Il cane selvaggio del Pleistocene di Sardegna, Geologica Romana, 1, 173189.

Marra, A.C., 2005. Pleistocene mammals of Mediterranean islands, Quaternary International, 129(1), 5-14.

Meiri, S., Dayan, T., and Simberloff, D., 2004. Body size of insular carnivores: little support for the island rule, American Naturalist, 163(3), 469-479.

Palombo, M.R., 2006. Biochronology of the Plio-Pleistocene terrestrial mammals of Sardinia: the state of the art, Hellenic Journal of Geosciences, 41(1), 47-66.

Palombo, M.R., in press. How can endemic elephants help us understanding "island rule"?, Quaternary International.

Reese, D.S., 1995. The Pleistocene vertebrate sites and fauna of Cyprus, Bulletin of the Geological Survey of Cyprus, 9, 1-203.

Simmons, A.H., 1999. Faunal extinction in an island society: pygmy hippopotamus hunters of Cyprus, New York, Kluwer, 381pp.

Simpson, G.G., 1940. Mammals and land bridges, Journal of the Washington Academy of Sciences, 30, 137-163.

Sondaar, P.Y., 1977. Insularity and its effect on mammal evolution. In M.K. Hecht, P.C. Goodyand and B.M. Hecht (eds), Major patterns in Vertebrate evolution. 671-707, New York, Plenum.

Sondaar, P.Y., and Boekschoten, G.J., 1967. Quaternary Mammals in the South Aegean island arc, with notes on other fossil Mammals from the coastal regions of the Mediterranean, Proceedings of the Koninklijke Nederlandse Akademie van Wetenschappen, 70(5), 556-576.

Sondaar, P.Y., de Vos, J., and Dermitzakis, M.D., 1986. Late Cenozoic faunal evolution and palaeogeography of the South Aegean island arc, Modern Geology, 10(2-3), 249-259.

Van Rompaey, H., 1988. Osbornictis piscivora, Mammalian Species, 309, 1-4.

Willemsen, G.F., 1992. A revision of the Pliocene and Quaternary Lutrinae from Europe, Scripta Geologica, 101, 1-115. 